\title{
Self-expandable metallic stents in nonmalignant large airway disease
}

\author{
Marc Fortin MD FRCPC, Paul MacEachern MD FRCPC, Christopher A Hergott MD FRCPC FCCP, \\ Alex Chee MD FRCPC, Elaine Dumoulin MD FRCPC, Alain Tremblay MDCM FRCPC FCCP
}

\author{
M Fortin, P MacEachern, CA Hergott, A Chee, E Dumoulin, \\ A Tremblay. Self-expandable metallic stents in nonmalignant large \\ airway disease. Can Respir J 2015;22(4):235-236.
}

\begin{abstract}
Airway self-expandable metallic stents (SEMS) were initially studied in malignant airway obstruction; however, their use in benign airway diseases has become progressively more frequent. This may be explained by their ease of insertion compared with silicone stents, which require rigid bronchoscopy for insertion. While initial experience with SEMS in benign disease suggested efficacy and promising short-term safety profile, longterm follow-up revealed significant complication rates. In addition to a high complication rate, the management of these complications is made more difficult by the semipermanent nature of these devices. Reported complications include infection, granulation tissue formation, stent migration, stent fracture, airway perforation and fistula formation, as well as extension of the initial injury, potentially eliminating other therapeutic options such as surgical resection. Therefore, SEMS should only be used in nonmalignant large airway disease as a last resort for patients in whom other endoscopic methods, including silicone stents and dilations, as well as surgical options have failed or are technically not feasible.
\end{abstract}

Key Words: Airway stent; Bronchoscopy; Tracheal stenosis

A irway stents can be used to treat central airway obstructions that are not amenable to resection or to preserve airway patency after it is re-established by an endobronchial debulking procedure. Their primary use has been in malignant disease to help manage malignant airway obstruction from tumour(s), either intrinsic or extrinsic. Stents can function as a supporting structure to an externally compressed airway or by forming a barrier to endoluminal growth of tissues. Because of their success with malignant disease, attempts have been made to also use stents in benign diseases such as postintubation tracheal stenosis, inflammatory stenosis or tracheobronchomalacia. The present short review highlights important aspects regarding the use of airway stents for nonmalignant central airway disorders, particularly regarding self-expandable devices.

One of the first airway stents developed was the Montgomery T-Tube, a silicone device with a tracheostomy limb, which allows easy access to the airway and helps maintain the stent in position (1). This was followed by 'stand alone' airway silicone stents first developed by Dumon (2), with variations of this design now available through several medical device companies. The stents are available in several lengths and diameters in including in ' $\mathrm{Y}$ ' configurations for simultaneous tracheal and bilateral mainstem stenting. Silicone stents have the advantage of being relatively inexpensive, available in a large variety of shapes and sizes and, most importantly, easy to remove at any time. They require rigid bronchoscopy to insert and remove, can cause problematic retention of secretions and can occasionally migrate. Airway placement of modified vascular metal stents was first attempted in the late 1980s (3-5); however, these devices had unacceptable complication rates (3). In the early 1990s, the initial experiences with the use of nitinol self-expandable metallic stents (SEMS) designed for airway placement were positive $(6,7)$. The most notable advantage of SEMS is that rigid bronchoscopy, while still preferred by many operators, is

\section{Les endoprothèses métalliques auto-expansibles en cas de maladies non cancéreuses des grosses voies respiratoires}

Les endoprothèses métalliques auto-expansibles (EMAE) ont d'abord fait l'objet d'études en cas d'obstruction cancéreuse de voies respiratoires. Cependant, leur utilisation s'est graduellement accrue pour trailer des maladies bénignes. C'est peut-être parce qu'elles sont plus faciles à insérer que les endoprothèses de silicone, qui nécessitent une bronchoscopie rigide. Les premières utilisations d'EMAE en cas de maladies bénignes laissaient croire à leur efficacité et à un profil prometteur à court terme, mais le suivi à long terme a révélé un taux élevé de complications. En outre, leur prise en charge est compliquée par la nature semi-permanente des endoprothèses. L'infection, la formation de tissus granuleux, la migration ou la fracture de l'endoprothèse, la perforation des voies respiratoires et la formation de fistules font partie des complications déclarées, de même que l'élargissement de la lésion initiale, qui peut écarter le recours à d'autres possibilités thérapeutiques comme la résection chirurgicale. Ainsi les EMAE devaient être utilisées en dernier recours en cas de maladie non maligne des grosses voies respiratoires, y compris après les endoprothèses de silicone et les dilatations, l'échec ou la non-faisabilité technique des interventions chirurgicales.

not required for insertion; therefore, they can be deployed with the assistance of a flexible bronchoscope, guidewires and fluoroscopy. The stents themselves are more costly than their silicone counterparts, have a thinner profile, resulting in a larger inner diameter for a given outer diameter size and are available either as uncovered mesh versions (allowing better mucociliary clearance but no barrier effect), or partly/ fully covered versions in a wide range of diameters and lengths. Initial reports demonstrated a high rate of symptom relief with a good shortterm safety profile, leading to more widespread use of SEMS, particularly for the palliation of malignant airway obstruction (4).

An important consideration with SEMS, especially in patients with a prolonged survival, such as is often the case in patients with nonmalignant indications, is that uncovered or partially covered devices become epithelialized several weeks after placement, making removal very difficult or impossible (5) - a significant drawback if and when complications arise. Concerns about their use in the benign setting were raised early after the availability of SEMS by Colreavy and Walsh (6), who stated in 2000: "we advise extreme caution in inserting these stents in patients with benign disease, in whom insertion should be regarded as permanent".

Those initial concerns have unfortunately been confirmed as published experience in the field has grown. The tendency of SEMS to cause more frequent complications in benign (versus malignant) disease has been noted in particular for granulation tissue formation ( $4 \%$ versus 33\%) (11). Another report, in which 211 SEMS were inserted in 149 patients ( 72 with benign and 77 with malignant diseases), also noted that the complication rate in the benign disease group was twice as high as in the malignant disease group ( $42.2 \%$ versus $21.1 \%)$, particularly with regard to granulation tissue formation $(19.0 \%$ versus $10.5 \%)$ and stent fracture ( $16.4 \%$ versus $1.1 \%)(7)$. Of additional concern was that approximately one in five procedures performed to 
treat complications were unsuccessful (8). A more recent case series, in which 82 metal stents were placed in 35 patients with benign disease, reported at least one complication in $77 \%$ of patients treated (9). One explanation for the increased rate of complications is that such patients will usually have a much longer survival and follow-up period during which complications can arise. While certain complications occur early, others increase in incidence over time and, as such, will be less of an issue for patients with stents placed in the setting of palliation for advanced cancer and short life expectancy (10).

One of the best studied benign indication for SEMS has been in the setting of lung transplant anastomotic pathology. This population may represent a different subgroup in the benign airway diseases due to their immunosuppressed status, which could influence complications such as granulation tissue formation and infections. Long-term followup of this patient cohort has been reported, with some authors suggesting effectiveness and low complication rates (11) while others report higher complication rates, such as mucous plugging and restenosis, and higher mortality than for transplant patients without anastomotic problems (12). No comparative studies comparing outcomes of SEMS with silicone stents exist in this setting.

In addition to the possible direct complications of SEMS, it is important to note that the placement of such devices may limit future therapeutic options such as surgical resection. A descriptive study of 15 patients referred to a specialized centre for management of SEMSrelated complications in the benign setting found that some degree of stricture and/or granulation tissue formation in areas that were normal before stent insertion was observed in all cases. Of concern was that three of 10 cases believed to have been candidates for surgical resection before stent placement could no longer proceed due to the extension of injury introduced by the devices (13).

While SEMS can, in some cases, be removed to manage complications refractory to other treatments, this is a significantly more difficult undertaking than for silicone devices. Interestingly, the need for removal is more common for benign diseases $(9,17)$. The largest series published to date described the removal of 55 SEMS in 46 patients using rigid bronchoscopy and suggested that this is, in fact, possible in the vast majority of cases but comes at a certain cost (14). Stent removal was possible in all except one individual; however, the complication rate of removal was high (58\%), with $46 \%$ of patients requiring the insertion of a new silicone stent for mucosal tears or obstruction secondary to edema or malacia. The median total cost per encounter to remove the stents was $\$ 10,700$ and the associated mortality rate was $4 \%$.

Based on some of the above concerns, in 2005, the United States Food and Drug Administration published a public health notification warning physicians of the potential for complications from SEMS when used in benign diseases (15). Several recommendations were made, which remain appropriate a decade later:

- Use metallic tracheal stents in patients with benign airway disorders only after thoroughly exploring all other treatment options.

- Using metallic tracheal stents as a bridge to other therapies is not recommended because removal of the metallic stent can result in serious complications.

- If a metallic tracheal stent is the only option for a patient, insertion should be performed by a physician trained or experienced in metallic tracheal stent procedures.

- If removal is necessary, the procedure should be performed by a physician trained or experienced in removing metallic tracheal stents.

Since that time, fully covered nitinol stents have been marketed, which may combine the ease of insertion associated with SEMS with the removability of silicone devices. Nevertheless, other complications, such as migration, granulation tissue formation, infection and stent fractures, remain and the published experience with such devices to date is minimal and not particularly reassuring, especially for benign diseases and, as such, their use should follow the same cautious approach described above (16-18).

\section{CONCLUSION}

SEMS can be effective at relieving symptoms in selected cases of nonmalignant large airway diseases but can lead to a high rate of complications including infections, granulation tissue formation, stent migration, stent fracture, airway perforation and fistula formation when left in situ for a prolonged period. Their removal has been demonstrated to be costly and associated with a high complication rate. Therefore, their use represents a treatment of last resort for patients with benign airway diseases, limiting life expectancy or causing significant impact on quality of life in whom endoscopic procedures without instrumentation (simple dilation), silicone stent placement and/or surgical interventions are unsafe, ineffective or impossible due to comorbidities or the nature of the lesion. When the insertion of a stent is contemplated for a benign disease, silicone stents should be considered as a first choice due to their favourable safety profile and ease of removal. Before the insertion of a SEMS for a benign disease, every patient should receive comprehensive explanations about short- and long-term risks of these devices and potential alternatives to the procedure. Preferably, such patients should be evaluated in a multidisciplinary team environment with experience in the management of benign central airway pathology, airway surgery, and both silicone stent and SEMS placement and management.

\section{REFERENCES}

1. Montgomery WW. T-tube tracheal stent. Arch Otolaryngol 1965;82:320-1.

2. Dumon JF. A dedicated tracheobronchial stent. Chest 1990;97:328-32.

3. Rousseau H, Dahan M, Lauque D, et al. Self-expandable prostheses in the tracheobronchial tree. Radiology 1993;188:199-203.

4. Dasgupta A, Dolmatch BL, bi-Saleh WJ, Mathur PN, Mehta AC. Self-expandable metallic airway stent insertion employing flexible bronchoscopy: Preliminary results. Chest 1998;114:106-9.

5. Lunn W, Feller-Kopman D, Wahidi M, Ashiku S, Thurer R, Ernst A. Endoscopic removal of metallic airway stents. Chest 2005;127:2106-12.

6. Colreavy MP, Walsh MA. Nitinol Tracheobronchial stents: A word of caution. Laryngoscope 2000;110:1070.

7. Chung FT, Chen HC, Chou CL, et al. An outcome analysis of selfexpandable metallic stents in central airway obstruction: A cohort study. J Cardiothorac Surg 2011;6:46.

8. Chung FT, Chen HC, Chou CL, et al. An outcome analysis of selfexpandable metallic stents in central airway obstruction: A cohort study. J Cardiothorac Surg 2011;6:46.

9. Chan AL, Juarez MM, Allen RP, Albertson TE. Do airway metallic stents for benign lesions confer too costly a benefit? BMC Pulm Med 2008;8:7.

10. Chung FT, Chen HC, Chou CL, et al. An outcome analysis of selfexpandable metallic stents in central airway obstruction: A cohort study. J Cardiothorac Surg 2011;6:46.

11. Gottlieb J, Fuehner T, Dierich M, Wiesner O, Simon AR, Welte T. Are metallic stents really safe? A long-term analysis in lung transplant recipients. Eur Respir J 2009;34:1417-22.

12. Abdel-Rahman N, Kramer MR, Saute M, Raviv Y, Fruchter O. Metallic stents for airway complications after lung transplantation: Long-term follow-up. Eur J CardioThorac Surg 2014;45:854-8.

13. Gaissert HA, Grillo HC, Wright CD, Donahue DM, Wain JC, Mathisen DJ. Complication of benign tracheobronchial strictures by self-expanding metal stents. J Thorac Cardiovasc Surg 2003;126:744-7.

14. Alazemi S, Lunn W, Majid A, et al. Outcomes, health-care resources use, and costs of endoscopic removal of metallic airway stents. Chest 2010;138:350-6.

15. FDA public health notification: Complications from metallic tracheal stents in patients with benign airway disorders. $</$ www.fda.gov/MedicalDevices/Safety/AlertsandNotices/ PublicHealthNotifications/ucm062115.htm> (Accessed May 5, 2015).

16. Marchese R, Poidomani G, Paglino G, Crimi C, Lo Nigro C, Argano V. Fully covered self-expandable metal stent in tracheobronchial disorders: Clinical experience. Respiration 2015;89:49-56.

17. Tan JH, Fidelman N, Durack JC et al. Management of recurrent airway strictures in lung transplant recipients using AERO covered stents. J Vasc Intervent Radiol 2010;21:1900-4.

18. Dooms C, De KT, Janssens A, Carron K. Performance of fully covered self-expanding metallic stents in benign airway strictures. Respiration 2009;77:420-6. 


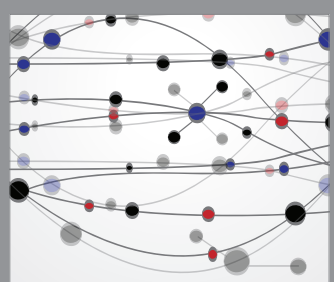

The Scientific World Journal
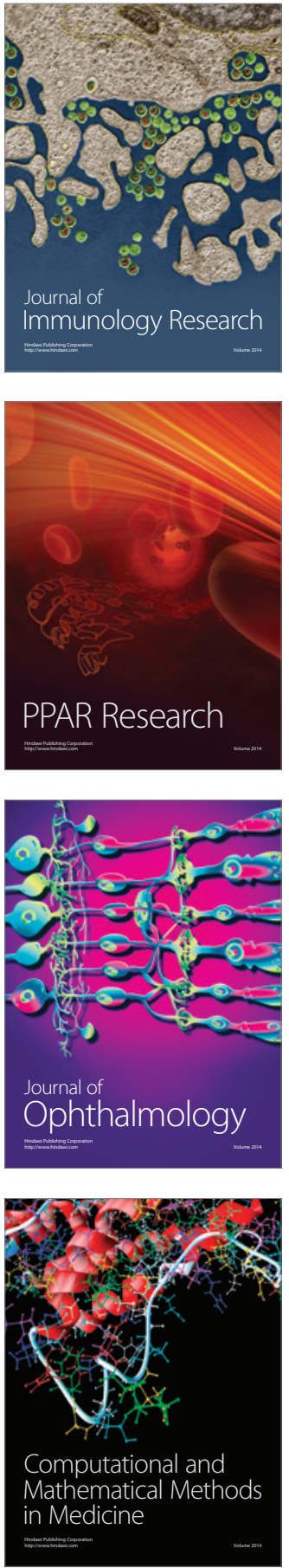

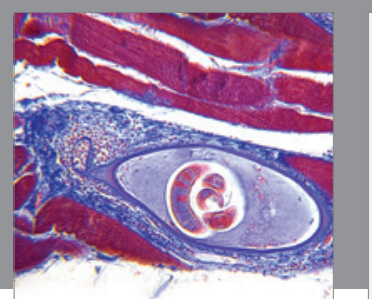

Gastroenterology Research and Practice

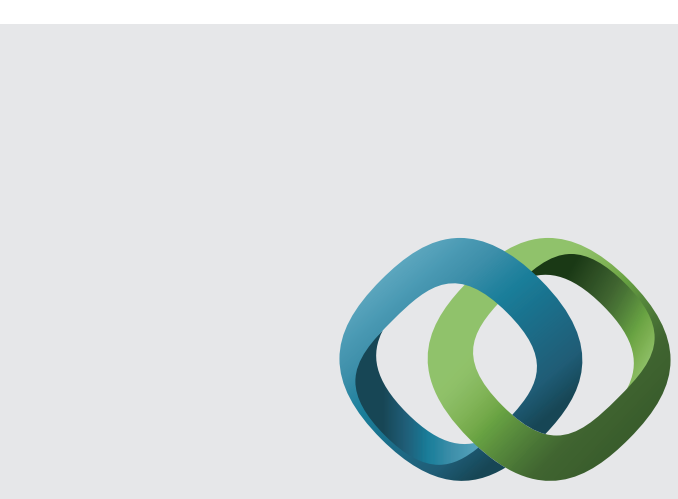

\section{Hindawi}

Submit your manuscripts at

http://www.hindawi.com
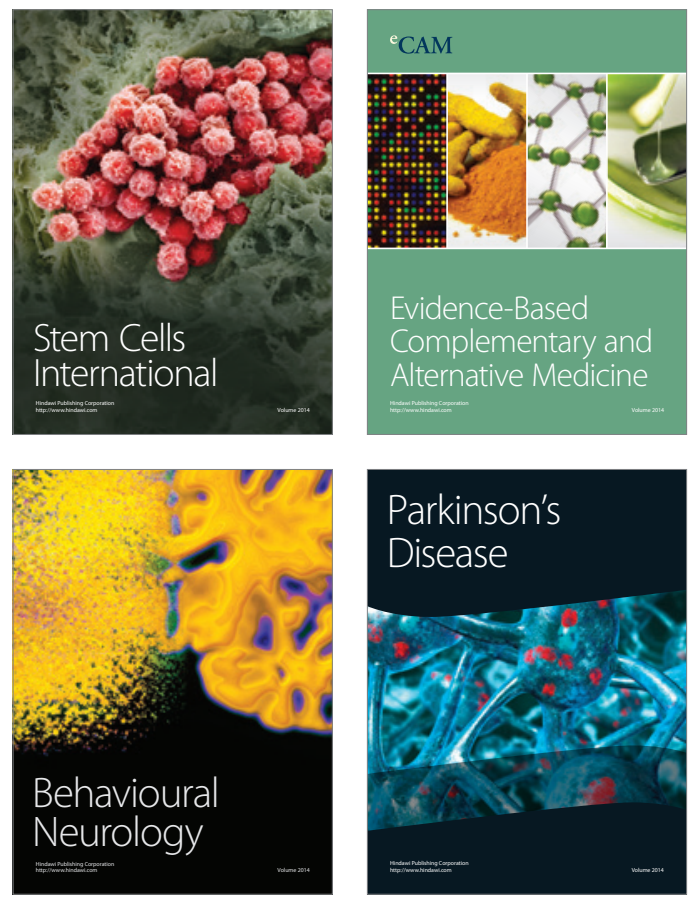
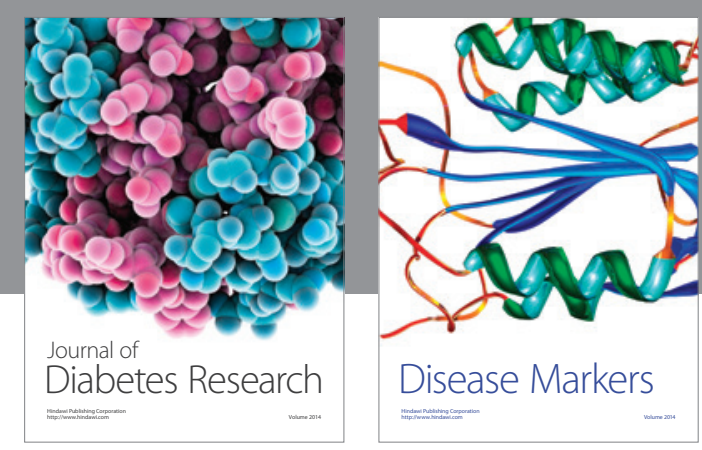

Disease Markers
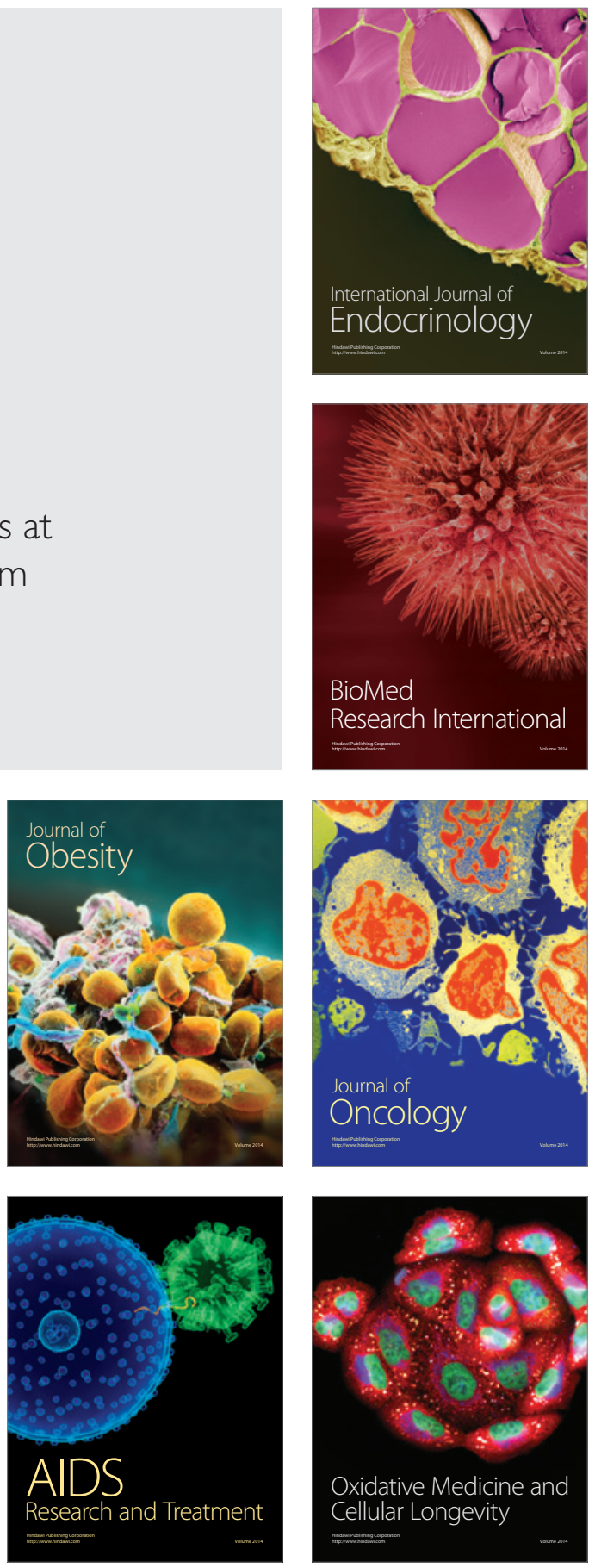